\title{
Clinical Test of Pyrroles in Psychiatric Disorders: Association with Nutritional, Immunological and Metabolic Markers
}

\author{
Nina Mikirova*
}

Riordan Clinic, 3100, N Hillside, Wichita, KS, USA

\begin{abstract}
Background: Psychiatrists started using urine pyrroles (hydroxyhemopyrrolin-2-one, HPL) to diagnose psychiatric disorders many years ago. The biological origins of HPL are not known, nor are the causes of elevated urinary pyrrole excretion well understood.

Methods: In the present study we analyzed the level of pyrroles in 148 patients with schizophrenia, 135 patients with bipolar disorder, 97 patients with depression, 119 patients with ADHD and compared these data with the results of pyrrole tests for patients with non-psychiatric conditions and healthy volunteers.

Results: According to our data, urinary pyrrole concentrations tended to be high in patients with psychiatric disorders, but elevated level of pyrroles was not specific for only these patients. We found evidence of an allergy related component in the fact that elevated pyrrole levels were significantly more prevalent in subjects with elevated histamine values. A role of intestinal bacteria, or imbalances in intestinal bacterial metabolism, was also suggested based on the found relationship between elevated pyrrole levels and elevations in indicans and urobilinogens. In addition, our data demonstrated that subjects with severely elevated pyrrole levels were deficient in nutrients such as zinc, vitamin B3, and vitamin C.
\end{abstract}

Conclusion: Thus, pyrrole excretion seems to be a component of illness in general and not strictly psychiatric disorders.

Keywords: Pyrroles, indicans, urobilinogens, histamine, nutrient deficiency, psychiatric disorders.

\section{INTRODUCTION}

Interest in pyrroles as markers of psychiatric disorders started Dr. Abram Hoffer's discovery that "Mauve Factor", a pyrrole named for its lavender appearance in urine chromatograms stained with Ehrlich's reagent [1], was prominent in urine samples from schizophrenics [2, 3]. After considerable efforts [410], Mauve Factor was determined to be the hemopyrrole derivative hydroxyhemopyrrolin-2-one (HPL). Hoffer claimed that HPL tended to decrease when a patient recovered from illness, and increased when illness reappeared; moreover, treatments with vitamin B6 and zinc were reported to decrease HPL levels and were associated with patient recovery [11]. Some psychiatrists, particularly those with interests in orthomolecular medicine, have used HPL as a clinical tool for diagnosing and following the progression or remission of mental illness [11-17]. Data from these studies suggest that roughly one-third of schizophrenia patients tested had elevated pyrroles, but high urine HPL levels were not limited to schizophrenia, as a variety of conditions and stresses were associated with urine pyrrole excretion.

The biological origins of HPL are not known, nor are the causes of elevated urinary pyrrole excretion understood. Proposed mechanisms for HPL formation and accumulation in the body include intake from

*Address correspondence to this author at the Riordan Clinic, 3100, N Hillside, Wichita, KS, USA; Tel: 316927 4753; E-mail: nmikirova@riordanclinic.org dietary sources, heme breakdown, or altered heme biosynthesis, the latter perhaps occurring with the aid of gut flora [18]. Irvine has proposed that HPL is a metabolite of heme synthesis intermediates porphobilinogen and prophyrins, as these are structurally very similar to HPL [9]. Increases in pyrrole levels and excretion may occur as a result of stress-induced changes in intestinal permeability, which in turn leads to increased pyrrole absorption. To the extent that pyrrole excretion may be an indicator of heme breakdown due to emotional stress, oxidative stress, or nutrient deprivation, a study of the correlation between urinary pyrroles and nutrient levels should be of interest.

Urine HPL levels can be quantified using a colorimetric assay, provided precautions are taken to keep it stable prior to and during the assay. At the Riordan Clinic, urinary pyrrole measurements have been part of the protocol for diagnosing psychiatric disorders and other disorders for decades. Access to the clinic's database has enabled us to examine pyrrole levels in patients with a variety of disorders and to see how they correlate with the concentrations of other key nutrients or metabolites. The present manuscript describes our analysis and evaluation of these data, and provides some assessment of the potential value of monitoring pyrrole levels in patients with psychiatric disorders.

\section{METHODS}

All laboratory tests were conducted by the Riordan Clinic Bio-Center Laboratory (Wichita, KS), a licensed 
and certified medical laboratory that offers over onehundred laboratory tests (http://www.riordanclinic.org/ laboratory/catalog.pdf). Handling of laboratory data by our institute is done in full compliance with HIPAA regulations. Assay methods for the various vitamins, minerals, and lipids for which data are presented here were conducted by the Bio-Center Laboratory using standard methodologies. For measurement of urine $\mathrm{HPL}$, urine was stabilized with ascorbic acid $(8 \mathrm{~mL}$ urine added to $500 \mathrm{mg}$ of ascorbic acid) and frozen to ensure HPL stability. Pyrroles were them extracted from urine with chloroform and reacted with Ehrlich's aced aldehyde reagent $(0.5 \mathrm{~g}$ of p-dimethylaminobenzaldehyde, $2.5 \mathrm{ml}$ sulfuric acid in $50 \mathrm{ml}$ of methanol). This preparation yields a chromophore with an absorption maximum of $540 \mathrm{~nm}$, which is related to HPL concentration using a standard curve [18]. Data from the Bio-Center Laboratory were obtained using the LabNet program (Henry Schein, Melville NJ). Statistical analyses were carried out using the Excel spreadsheet program and graphs, with regression data fits where appropriate, were constructed using the Kalaidagraph program (Synergy Software, Reading PA).

Inclusionary criteria used were patients with a diagnosis of psychiatric disorder who came for treatment at the Riordan Clinic and had evaluations that included nutritional and pyrrole tests. No other demographic data except ages and sex were recorded for this study.

The diagnosis of psychiatric disorder was made by medical doctors using Diagnostic and Statistical Manual of Mental Disorders-IV criteria based on direct observations plus reports from parents and other care takers.

\section{RESULTS}

We analyzed urine pyrrole data in 119 patients with ADHD, 148 patients with schizophrenia, 135 patients with bipolar disorder and 97 patients with depression. We first examined parameters that are key precursors for neurotransmitters (amino acids) or have been cited as being potentially relevant to psychiatric disorders, such as toxic metals, essential minerals, and fatty acids. The average values of these tests are shown in Table 1. In addition, the normal range (average $\pm 1 S D$ ) for each test presented in the second column of Table 1 .

Tests for psychiatric disorder groupings show elevated average values of hair aluminum, lead (in patients with schizophrenia), iron (total and hair), arachidonic acid to EPA ratio, omega 3 to omega 6 fatty acid ratios, and urine pyrroles. Deficiencies were found in the levels of essential metals magnesium, zinc and copper (serum). Some deficiencies and the metabolic imbalances in fatty acid, amino acid, mineral, and pyrrole levels in ADHD patients were analyzed previously [19].

The percentage of patients with increased levels of pyrroles in comparison with patients without specific diagnosis (134 healthy subjects) is shown in Figure 1.

According to these data the percentage of patients with the levels of pyrroles higher than $20 \mathrm{ug} / \mathrm{dL}$ was $48 \%$ for ADHD patients, $22 \%$ for patients with schizophrenia, $30 \%$ for patients with bipolar and depression and $26 \%$ for patients without specific diagnosis.

Pyrrole distributions in subjects with illnesses were analyzed by illness category, along with the distribution that would be expected if all subjects were in the normal range. There was skew in the data indicating subjects with elevated pyrrole levels. It is particularly acute in ADHD patients, of whom $48 \%$ had levels above the normal range (Figure 2).

The mean of pyrrole values outside the normal range were $47 \mathrm{ng} / \mathrm{dL}$ for patients with schizophrenia, 43 $\mathrm{ng} / \mathrm{dL}$ for patients with bipolar disorder, $39 \mathrm{ng} / \mathrm{dL}$ for patients with depression and $44 \mathrm{ng} / \mathrm{dL}$ for patients with ADHD.

The highest level was measured for a 10-year old boy $(481 \mathrm{ug} / \mathrm{dL})$. A level of $192 \mathrm{ug} / \mathrm{dL}$ was found in 5 year old girl and levels of $123 \mathrm{ug} / \mathrm{dL}$ and $114 \mathrm{ug} / \mathrm{dL}$ in two boys. The proportion of subjects with pyrroles outside the normal range was similar to those seen in patients with other illnesses (26\% of all subjects analyzed had pyrrole levels above $20 \mathrm{ug} / \mathrm{dL}$ ), suggesting that pyrrole levels indicate illness in general and not necessarily psychiatric disorder.

To see if pyrrole levels were related to allergic reactions, we compared pyrrole levels with histamine and immunoglobulin levels. For histamine, data are shown in Figure $\mathbf{3 a}, \mathbf{b}$.

There was a statistically significant correlation $(p<$ 0.001 ) between histamine levels and pyrrole levels, and the vast majority of patients with elevated pyrrole levels showed elevated histamine levels also. For instance, for subjects with histamine levels below 
Table 1: Mean Values of Various Laboratory Test Parameters for Subject with Different Types of Psychiatric Disorders

\begin{tabular}{|c|c|c|c|c|c|c|c|c|c|c|c|}
\hline \multicolumn{2}{|c|}{ Parameter and Units } & \multirow{2}{*}{$\begin{array}{c}\begin{array}{c}\text { Normal } \\
\text { range }\end{array} \\
\text { Low }\end{array}$} & \multirow{2}{*}{$\begin{array}{l}\text { 1SD } \\
\text { High }\end{array}$} & \multicolumn{8}{|c|}{ Mean and Standard Deviation Values } \\
\hline & & & & \multicolumn{2}{|c|}{ ADHD } & \multicolumn{2}{|c|}{ Schizophrenia } & \multicolumn{2}{|c|}{ Bipolar } & \multicolumn{2}{|c|}{ Depression } \\
\hline Homocysteine & (uM) & 7.5 & 12.5 & 6.9 & 1.6 & 9.7 & 3.2 & 9.1 & 3.0 & 9.1 & 3.0 \\
\hline Tryptophan & umol/dL & 0.9 & 1.8 & 1.4 & 1.0 & 1.3 & 1.2 & 1.3 & 1.1 & 1.4 & 0.9 \\
\hline Phenylanine & umol/dL & 4.1 & 7.8 & 5.6 & 1.4 & 6.2 & 1.8 & 5.8 & 1.3 & 5.6 & 1.4 \\
\hline \multicolumn{2}{|l|}{ Minerals } & Low & High & \multicolumn{2}{|c|}{ ADHD } & \multicolumn{2}{|c|}{ Schizophrenia } & \multicolumn{2}{|c|}{ Bipolar } & \multicolumn{2}{|c|}{ Depression } \\
\hline Iron (total) & $\mathrm{ug} / \mathrm{dL}$ & 40.8 & 100.3 & 101.9 & 51.8 & 88.7 & 34.0 & 88.7 & 38.3 & 90.4 & 35.6 \\
\hline Iron (hair) & ppm & 4.6 & 10.6 & 10.3 & 6.3 & 10.5 & 12.6 & 7.4 & 3.6 & 9.9 & 7.8 \\
\hline Magnesium (hair) & ppm & 56.5 & 125.5 & 37.6 & 39.2 & 47.7 & 49.1 & 75.6 & 91.6 & 99.8 & 143.0 \\
\hline Zinc (RBC) & $\mathrm{ug} / \mathrm{mL}$ & 9.5 & 14.9 & 10.0 & 2.1 & 11.7 & 1.6 & 11.9 & 2.0 & 11.9 & 1.7 \\
\hline $\mathrm{Zn}: \mathrm{Cu}$ & ratio & & & 9.3 & 5.5 & 6.5 & 7.9 & 11.8 & 4.6 & 12.1 & 5.2 \\
\hline \multicolumn{2}{|l|}{ Toxic metals } & Low & High & \multicolumn{2}{|c|}{ ADHD } & \multicolumn{2}{|c|}{ Schizophrenia } & \multicolumn{2}{|c|}{ Bipolar } & \multicolumn{2}{|c|}{ Depression } \\
\hline Lead (hair) & ppm & 0.0 & 1.6 & 0.9 & 1.4 & 3.2 & 7.2 & 1.2 & 3.1 & 1.4 & 2.1 \\
\hline Mercury (hair) & ppm & 0.0 & 1.6 & 0.2 & 0.3 & 0.6 & 0.5 & 0.4 & 0.4 & 0.6 & 0.5 \\
\hline Aluminum (hair) & ppm & 0.0 & 1.4 & 7.9 & 7.2 & 5.5 & 8.2 & 5.9 & 5.7 & 6.4 & 9.7 \\
\hline Arsenic (hair) & ppm & 0.0 & 0.6 & 0.1 & 0.2 & 0.3 & 0.1 & 0.2 & 0.2 & 0.2 & 0.2 \\
\hline \multicolumn{2}{|l|}{ Urine Parameters } & Low & High & \multicolumn{2}{|c|}{ ADHD } & \multicolumn{2}{|c|}{ Schizophrenia } & \multicolumn{2}{|c|}{ Bipolar } & \multicolumn{2}{|c|}{ Depression } \\
\hline $\mathrm{Na}: \mathrm{K}$ (urine) & ratio & 0.8 & 4.0 & 3.7 & 3.4 & 1.8 & 1.0 & 4.4 & 3.5 & 5.8 & 6.4 \\
\hline Pyrroles (urine) & $\mathrm{ug} / \mathrm{dL}$ & 0.0 & 15.0 & 29.2 & & 25.4 & 27.9 & 19.9 & 19.7 & 20.7 & 20.6 \\
\hline
\end{tabular}

$53 \mathrm{ng} / \mathrm{dL}$ (the upper limit of normal range in our clinical laboratory), only $16 \%$ of subjects had elevated (> 20 $\mathrm{ug} / \mathrm{dL}$ ) pyrrole levels, with only $2 \%$ having pyrrole values above $40 \mathrm{ug} / \mathrm{dL}$ and $2 \%$ having values above 80 $\mathrm{ug} / \mathrm{dL}$. In contrast, $26 \%$ of subjects with elevated histamine levels had elevated pyrrole levels, with $9 \%$ showing values above $40 \mathrm{ug} / \mathrm{dL}$ and $4 \%$ showing values above $80 \mathrm{ug} / \mathrm{dL}$. All subjects with pyrrole levels above $100 \mathrm{ug} / \mathrm{dL}$ had elevated histamine levels. Similar trends were observed with the immunoglobulins IgM. Relation between $\operatorname{lgM}$ and pyrroles is shown in Figure 4.
For abnormal levels of pyrroles ( $>20 \mathrm{ug} / \mathrm{dL}$ ), $75 \%$ of data were in the range of $\mathrm{lgM}$ higher than $100 \mathrm{mg} / \mathrm{dL}$. Average level of pyrroles was $30 \mathrm{ng} / \mathrm{dl} \pm 8 \mathrm{ng} / \mathrm{dl}$ for $\operatorname{lgM}<100 \mathrm{mg} / \mathrm{dl}$ and $46 \mathrm{ng} / \mathrm{dl} \pm 40 \mathrm{ng} / \mathrm{dl}$ for $\lg \mathrm{M}>100$ $\mathrm{mg} / \mathrm{dL}$.

Elevated pyrroles are also thought to be related to intestinal issues. The urine indican test is considered an indicator of intestinal toxemia and overgrowth of anaerobic bacteria (indican is a product of bacterial tryptophan digestion), while urobilinogens are products of intestinal bacteria that can build up if the liver is overburdened. Figure $\mathbf{5}$ shows how these parameters 


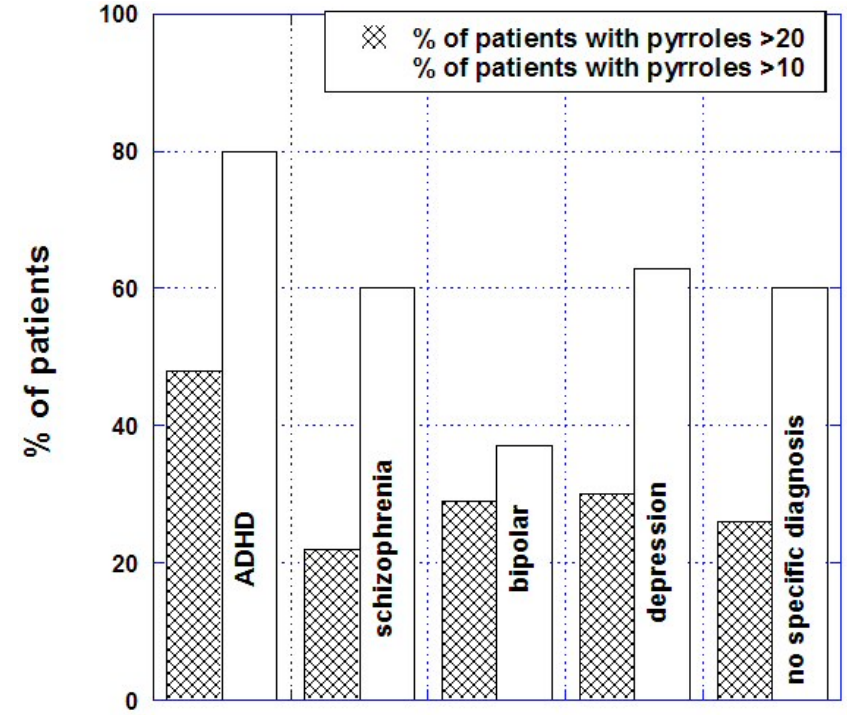

Figure 1: Frequency of the increased levels of pyrroles measured in patients with psychiatric disease and subjects without specific diagnosis.

vary depending on urinary pyrrole levels. In both cases, elevated pyrroles are associated with elevated levels, supporting the hypothesis that intestinal bacteria overgrowth may be associated with excessive pyrrole excretion.

To determine if increased pyrroles secretion is accompanied by nutritional deficiencies, we compared urinary pyrrole concentrations with vitamins and minerals in blood for cases where both were measured

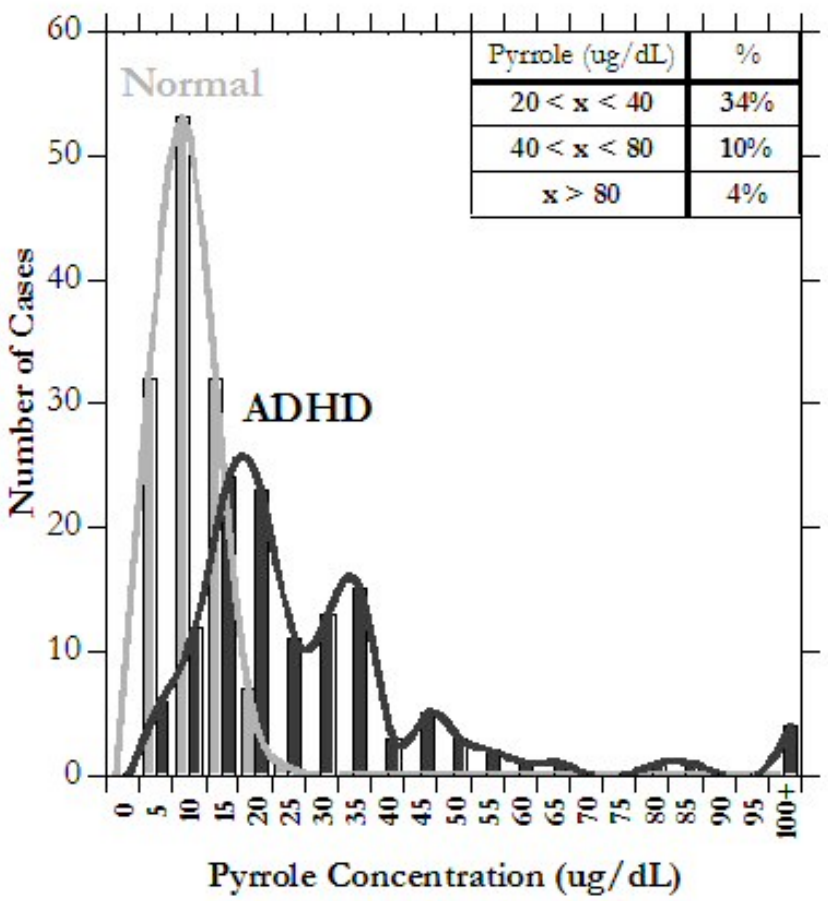

Figure 2: Distributions of urine pyrrole levels $\mathrm{ug} / \mathrm{dL}$ ) in subjects with ADHD. Tables within graphs show breakdown of normal and elevated pyrrole levels. Normal curve is normalized to match the total number of subjects.

on the same visit. Vitamins are natural barriers against infection and allergic reactions, as well as chemical balance of essential minerals. Examples where a relationship was particularly noticeable are shown in Figure 6.

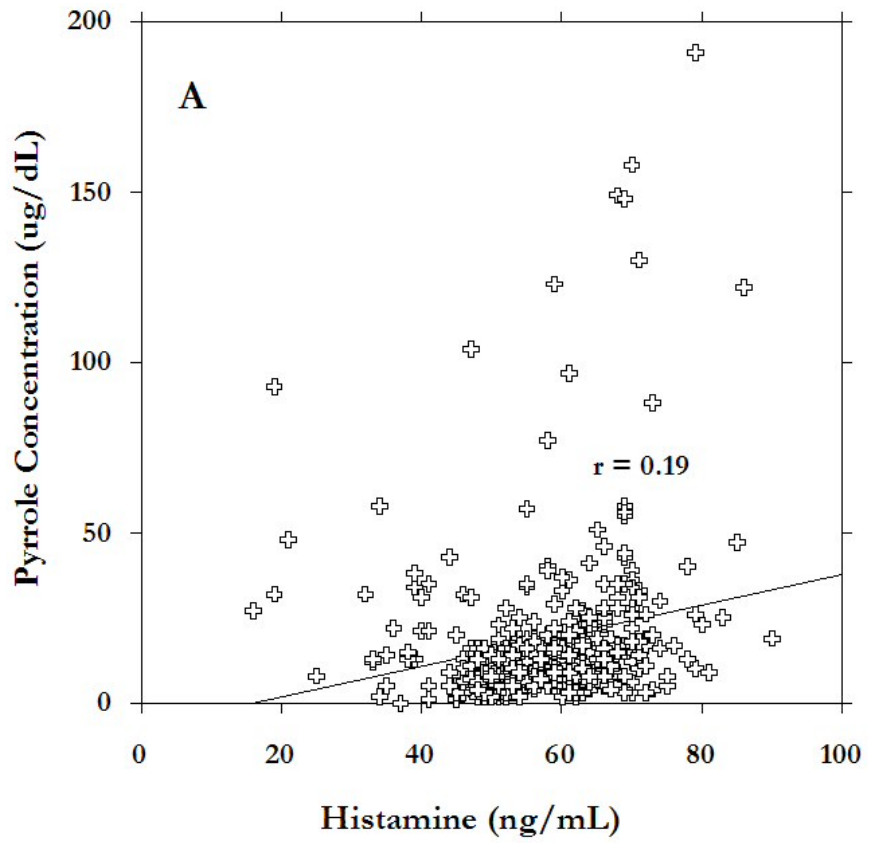

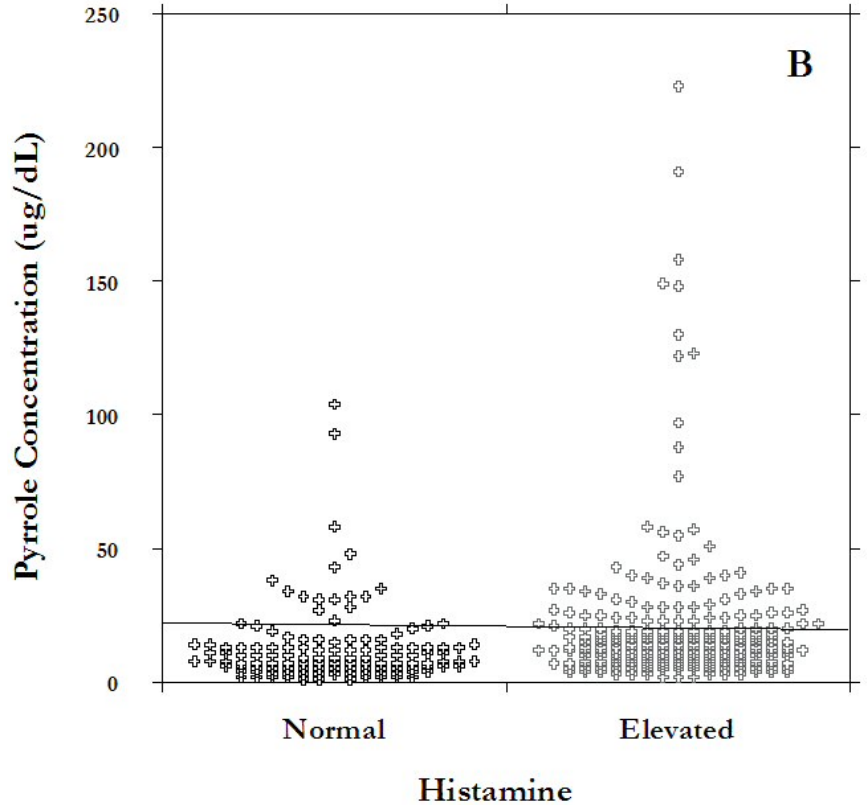

Histamine

Figure 3: Correlation between urine pyrrole levels and histamine in subjects with mental illnesses. (A) A linear scatter plot, with a least-squares regression line $(r=0.19$, p-value $<0.0001)$. (B) A dot plot showing pyrrole distributions for normal versus elevated (> $53 \mathrm{ng} / \mathrm{dL}$ ) histamine levels. 


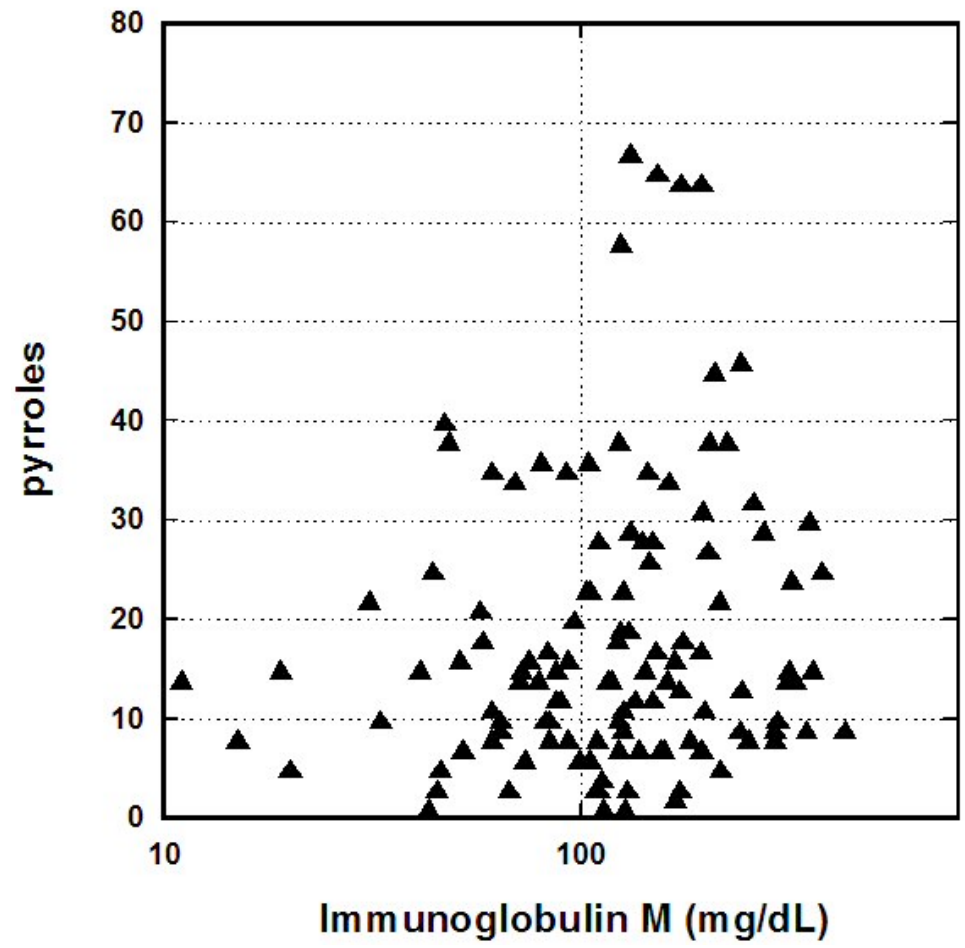

Figure 4: The relation between urinary pyrrole concentrations and Immunoglobulin M levels.
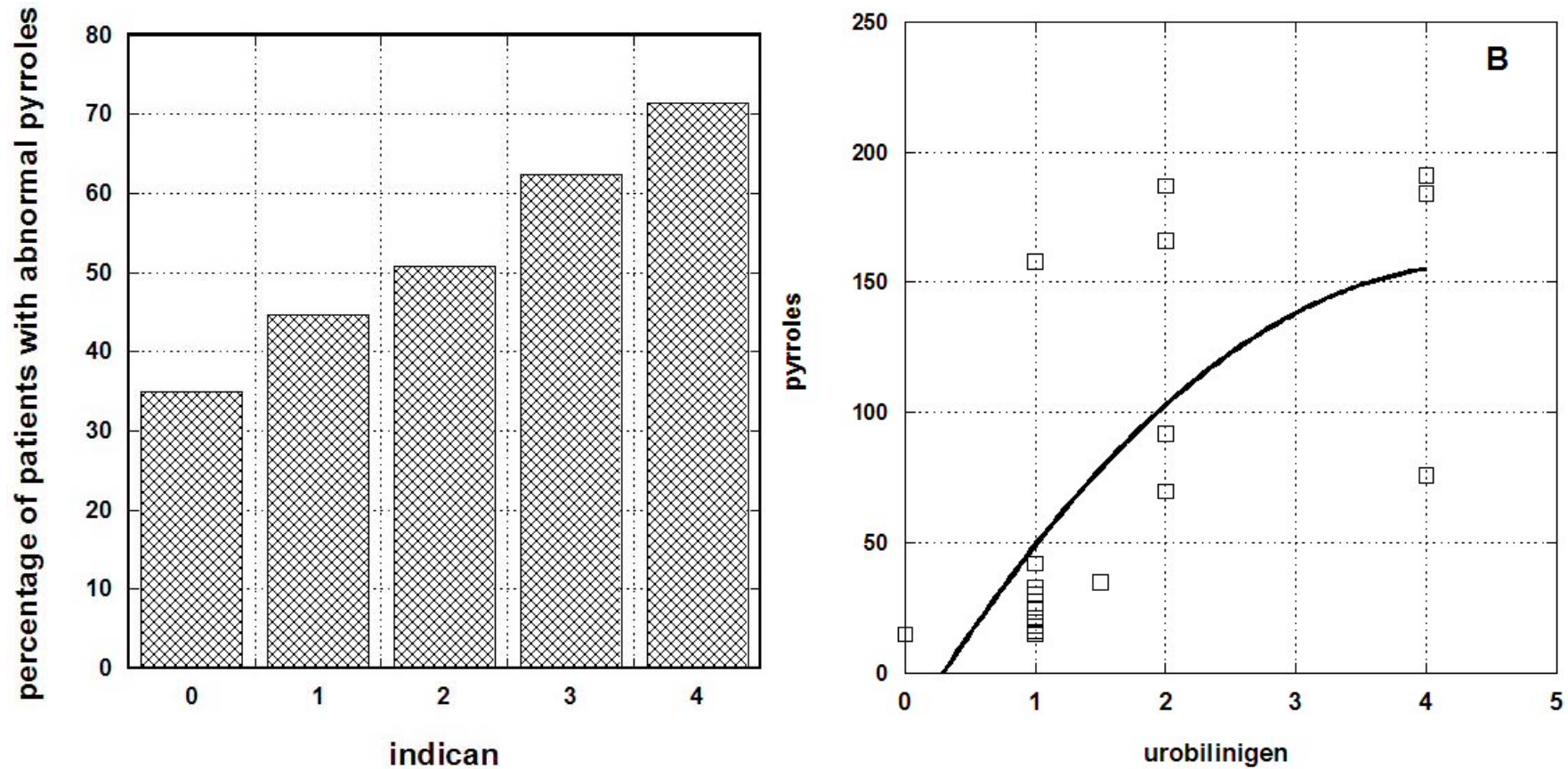

Figure 5: The relation between percentage of patients with abnormal urinary pyrroles and indican concentrations $(\mathbf{A})$ or urine indican concentrations and uribilinigen concentrations (B).

Vitamin C, vitamin B3, red blood cell zinc, and zinc to copper ratios were found in some psychiatric disorder groups to decrease with increasing pyrrole levels. Examining Figure 6, it appears that subjects with very high pyrrole levels (above $40 \mathrm{ug} / \mathrm{dL}$ ) tended toward the left hand side of the horizontal axis, suggesting that data points with very high pyrrole levels had low nutrient values. The potential link between nutrient levels and pyrrole levels deserves further more systematic study.

At the Riordan Clinic, patients with psychiatric disorders are sometimes treated by attempting to restore proper mineral balances and correct nutrient 

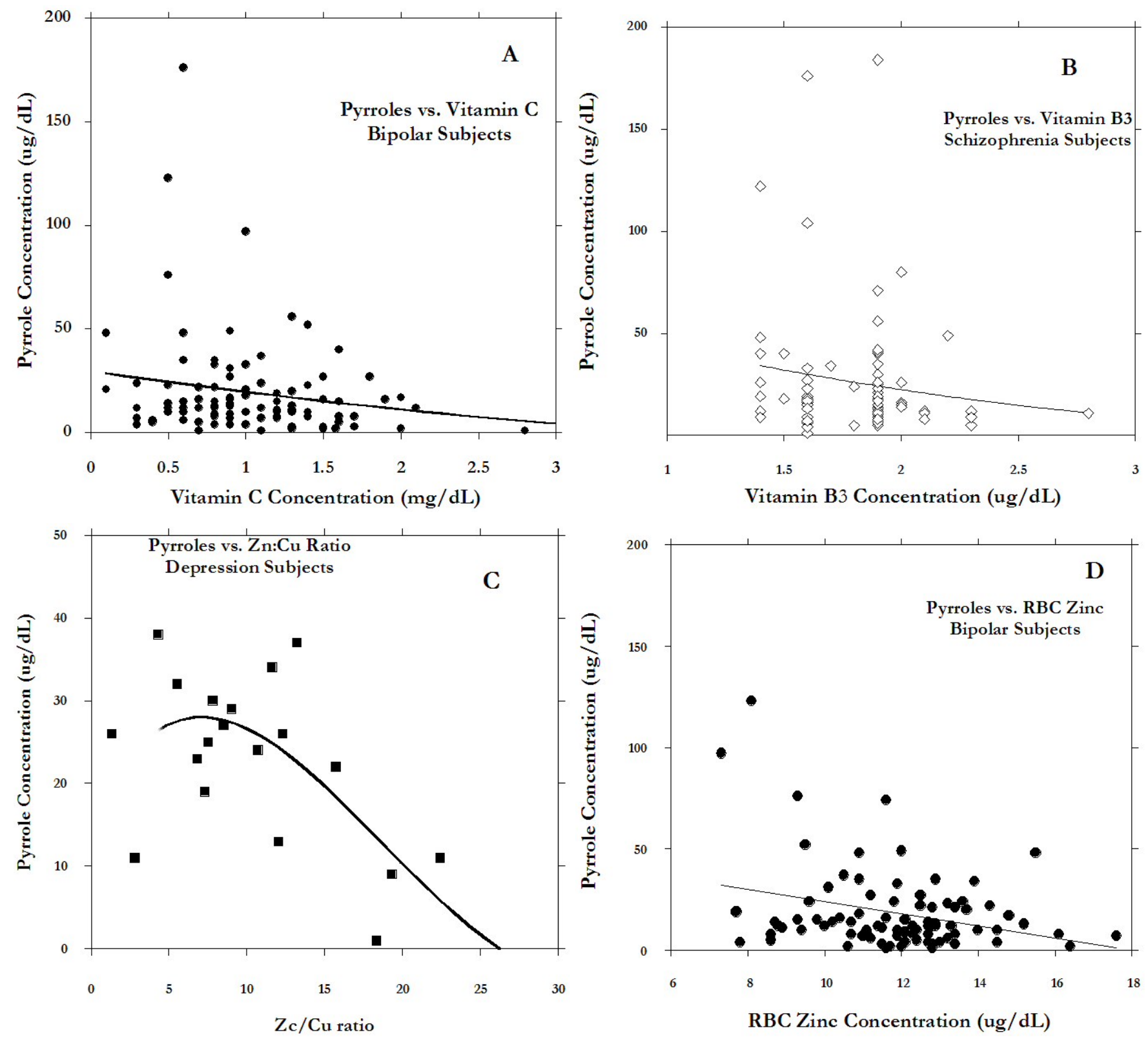

Figure 6: Effect of various nutrient levels on pyrrole excretion: (A) plasma vitamin C levels in bipolar subjects; (B) plasma vitamin B3 levels in schizophrenia subjects; (C) zinc to copper ratios in RBCs of depression subjects; and (D) RBC zinc levels in bipolar subjects. The lines represent linear (D) or quadratic (A, B, C) data fits, and are for illustration purposes only.

deficiencies. In particular, the integrative approach to the treatment of elevated pyrroles includes: intravenous ascorbic acid $(5 \mathrm{~g}-15 \mathrm{~g})$, Plex IV INF, vitamin B6 IV infusion, fortified flax, super EPA, cod liver oil, zinc boost, lipoic acid, ProEFA, chelated magnesium, DHEA and amino acids (cysteine, glutamine, tyrosine, arginine). Other nutrients were added to assist in pyroluria include niacinamide, pantothenic acid, manganese, evening primrose oil and digestive enzymes. We examined the database for mental illness patients who underwent this type of therapy (though precise protocol details varied from subject to subject) and compared "initial" to "final" pyrrole values. Results are shown in Table 2.
These data suggest that pyrrole levels decreased during treatment. We have not yet conducted a controlled trial where a consistent treatment is used and patient mental illness (symptom severity) is also monitored over time.

\section{DISCUSSION}

The Riordan Clinic has been measuring nutrients, minerals, toxins and urine pyrrole concentrations as a diagnostic tool for over forty years. In examining laboratory parameters that are thought to be important in maintaining proper neurological function (see Table 1), we found several potential trouble signs in patients 
Table 2: Changes in Urine Pyrrole Concentrations in Subjects Treated with Prolonged Nutrient Supplementation at the Riordan Clinic. Data Show the Maximum Value of Measured Pyrroles, Period of Treatment and the Measured Value at the End of the Indicated Period

\begin{tabular}{|c|c|c|c|c|c|c|c|c|c|}
\hline Subjects & $\begin{array}{l}\text { Pyrrole } \\
\text { (max) }\end{array}$ & $\begin{array}{c}\text { Pyrrole } \\
\text { (end value) }\end{array}$ & $\begin{array}{l}\text { Days of } \\
\text { treatment }\end{array}$ & Diagnosis & Subjects & $\begin{array}{c}\text { Pyrrole } \\
\text { (max) }\end{array}$ & $\begin{array}{c}\text { Pyrrole } \\
\text { (end value) }\end{array}$ & $\begin{array}{l}\text { Days of } \\
\text { treatment }\end{array}$ & Diagnosis \\
\hline subject 1 & 40 & 26 & 130 & Schizophrenia & subject 18 & 31 & 9 & 22 & depression \\
\hline subject 2 & 85 & 20 & 150 & Schizophrenia & subject 19 & 77 & 32 & 200 & depression \\
\hline subject 3 & 40 & 17 & 82 & Schizophrenia & subject 20 & 41 & 17 & 150 & depression \\
\hline subject 4 & 100 & 30 & 110 & Schizophrenia & subject 21 & 75 & 10 & 80 & depression \\
\hline subject 5 & 30 & 12 & 64 & Schizophrenia & subject 22 & 52 & 30 & 50 & depression \\
\hline subject 6 & 130 & 23 & 380 & Schizophrenia & subject 23 & 58 & 40 & 100 & depression \\
\hline subject 7 & 44 & 3 & 50 & Schizophrenia & subject 24 & 35 & 15 & 150 & depression \\
\hline subject 8 & 48 & 29 & 200 & bipolar & subject 25 & 150 & 75 & 30 & depression \\
\hline subject 9 & 48 & 16 & 372 & bipolar & subject 26 & 200 & 10 & 250 & depression \\
\hline subject 10 & 97 & 56 & 379 & bipolar & subject 27 & 30 & 12 & 60 & depression \\
\hline subject 11 & 52 & 31 & 50 & bipolar & subject 28 & 45 & 5 & 80 & depression \\
\hline subject 12 & 49 & 21 & 177 & bipolar & subject 29 & 48 & 32 & 167 & ADHD \\
\hline subject 13 & 123 & 19 & 102 & bipolar & subject 30 & 41 & 19 & 95 & ADHD \\
\hline subject 14 & 35 & 8 & 90 & depression & subject 31 & 34 & 16 & 80 & ADHD \\
\hline subject 15 & 46 & 19 & 300 & depression & subject 32 & 112 & 14 & 90 & ADHD \\
\hline subject 16 & 93 & 50 & 73 & depression & subject 33 & 481 & 35 & 25 & ADHD \\
\hline subject 17 & 50 & 24 & 400 & depression & & & & & \\
\hline
\end{tabular}

with various types of psychiatric disorders. In particular, the tests demonstrated the elevated average values of aluminum, lead (in patients with schizophrenia), iron, arachidonic acid to EPA ratio, omega 3 to omega 6 fatty acid ratios, and urine pyrroles. Deficiencies were found in the levels of essential metals: magnesium, zinc and copper (serum). Urinary pyrrole concentrations also tended to be high in these patients. We investigated these elevated pyrroles further, finding that nearly half of the patients diagnosed with ADHD had pyrrole concentrations above the normal limit (20 $\mathrm{ug} / \mathrm{dL}$ ) in urine. The proportion was roughly one-third in subject with depression, bipolar disorder, or schizophrenia. Interestingly, that elevated level of pyrroles was not specific for only patients with psychiatric disorders. When we analyzed patients without mental diseases all together as a whole (with illnesses ranging from cancer to arthritis, fibromyalgia, and chronic fatigue, among others) and subjects without specific diagnosis, roughly a quarter of them have elevated urinary pyrrole levels. Thus, pyrrole excretion seems to be a component of illness in general and not strictly mental diseases. We are struck, though, by how high urine pyrroles can be in mentally ill subjects, with roughly ten percent having values above $40 \mathrm{ug} / \mathrm{dL}$ and, in the case of schizophrenics and ADHD sufferers, nearly $5 \%$ of subjects having values above $80 \mathrm{ug} / \mathrm{dL}$. We saw some patients with levels over 200 $\mathrm{ug} / \mathrm{dL}$.
Our examination of the Riordan Clinic database confirms some of the conventional wisdom about pyrrole excretion. We find evidence of an allergy component in the fact that elevated pyrrole levels were significantly more prevalent in subjects with elevated histamine values (Figure 3). Immunoglobulins also appear to correlate with pyrroles (IgM vs pyrroles).

A role of intestinal bacteria, or imbalances in intestinal bacterial metabolism, is also suggested based on the relationship between elevated pyrrole levels and elevations in indicans and urobilinogens (Figure 5). Indicans can be an indicator of protein digestion efficiency [18]. Patients with high urine indicans can be expected to have issues such as insufficient gastric hydrochloric acid, insufficient digestive enzymes, adverse food reactions, infection, or bacterial overgrowth. These problems are also consistent with elevated urobilinogens. Elevated urine pyrroles, as they correlate with these other stress factors, may simply be an indicator of metabolic stress in the body. It also appears to be a general rule that subjects with severely elevated pyrrole levels were deficient in nutrients such as nutrients zinc, vitamin B3, vitamin $C$ (Figure 6). The stress factors described above (infection, toxicity, etc.) may be factors in causing nutrient deficiency, or may be caused by nutrient deficiency. Vitamin $C$ in particular is important for innate and cell mediated immunity, as it protects 
neutrophils from oxidative damage. The zinc to copper ratio is also an indicator of oxidative stress. This redox variable is commonly outside its normal range in mentally ill subjects, and appears to correlate in some cases with pyrrole excretion.

At the Riordan Clinic, mentally ill subjects are sometimes treated with supplements (including injections of B-vitamins, and intravenous infusions of vitamin $\mathrm{C}$ ) to replenish depleted nutrient stores and provide for rejuvenation of the immune system. We were thus interested in how these treatments affected pyrrole levels. While we have not conducted a rigorous clinical study in this regard, we were able to extract from the database a group of subjects who had similar treatments and for whom pyrrole analyses before and after extended treatment were available. The results shown in Table 2, seem to suggest that pyrrole concentrations are reduced after prolonged supplementation therapy. This may be an interesting topic to explore with more rigorous controlled studies.

In summary, our analysis of the Riordan Clinic patient database suggests that pyroluria is relevant to a variety of stress and illness conditions, and, to the extent that these stresses are relevant in psychiatric disorders, is relevant to many mentally ill subjects. Abnormal pyrrole excretion appears to be an indicator of oxidative stress, infection, intoxication, or improper digestion. Moreover, our data suggest that it may be possible to reduce pyroluria using a supplementation treatment regimen such as that employed at the Riordan clinic.

\section{REFERENCES}

[1] Irvine DG. Apparently non-indolic Ehrlich-positive substances related to mental illness. J Neuropsychiat 1961; 2: 292-305.

[2] Hoffer A, Osmond H. Malvaria: a new psychiatric disease. Actapsychiat Scand 1963; 39: 335-336. http://dx.doi.org/10.1111/j.1600-0447.1963.tb07470.x

[3] Hoffer A. The presence of malvaria in some mentally retarded children. Arnl Ment Def 1963; 67: 730-732.

[4] Irvine DG, Bayne W, Miyashita H, Maimer JR. Identification of kryptopyrrole in human urine and its relation to psychosis. Nature (London) 1969; 224: 811-813. http://dx.doi.org/10.1038/224811a0
[5] Irvine DG. Mauve factor and 6-sulfatoxy skatole: two biochemical abnormalities associated with specific measures of psychiatric disease. Clin Chem 1963; 9: 444-445.

[6] Irvine DG, Bayne W, Miyashita $\mathrm{H}$. The main form of naturallyoccurring kryptopyrrole: its $5-\mathrm{OH}-2$-lactam, a product of pyrrolooxygenase. Report to the Psychiatric Research Meeting of the Saskatchewan Psychiatric Association 1973; 46-67.

[7] Irvine DG, Bayne W, Miyashita H, Majer JR. Identification of kryptopyrrole in human urine and its relation to psychosis. Nature 1969; 224: 811-813. http://dx.doi.org/10.1038/224811a0

[8] Sohler A, Beck R, Noval JJ. Mauve factor re-identified as 2.4dimethyl-3-ethyl pyrroleand its sedative effect on the CNS. Nature 1970; 228: 1318-1320. http://dx.doi.org/10.1038/2281318a0

[9] Irvine DG, Wetrerberg L. Kryptopyrrole-like substance in acute intermittent porphyria. Lancet 1972; 1201. http://dx.doi.org/10.1016/S0140-6736(72)92630-X

[10] Irvine DG, Wilson DL. Oxidized monopyrroles in porphyric disorders and related conditions. In: Doss, M. editor. Porphyrins in Human Diseases. 1st. Int. Porphyrin Meet. Frieburg/Br. Basel: Karger 1976; 217-224.

[11] Hoffer A. Malvaria, schizophrenia and the HOD test. Int $J$ Neuropsychiatry 1965; 2: 175-178.

[12] Pfeiffer CC, lliev V. Pyroluria, urinary mauve factor causes double deficiency of B6 and zinc in schizophrenics. Fed Am Soc Exp Biol 1973; 32: 276.

[13] Pfeiffer CC, Sohler A, Jenney EH. Treatment of pyroluric schizophrenia (malvaria) with large doses of pyridoxine and a dietary supplement of zinc. J Appl Nutr 1974; 26: 21-28.

[14] Irvine DG. Kryptopyrrole and other monopyrroles in molecular neurobiology. Int Rev Neurobiol 1974; 16: 145182. http://dx.doi.org/10.1016/S0074-7742(08)60196-8

[15] Sohler A, Holsztynska MS, Pfeiffer CC. A rapid screening test for pyroluria; useful indistinguishing a schizophrenic population. J Orthomolec Psychiatr 1974; 3: 273-279.

[16] Jackson JA, Riordan HD, Neathery S. Vitamin, blood lead, and urine pyrrole levels in Down syndrome. Am Clin Lab 1990; 1: 8-9.

[17] Sohler A, Renz RH, Smith S, Kaufman J. Significance of hydroxyskatole and mauve factor excretion in schizophrenia. Int J Neuropsychiatry 1967; 3: 327-331.

[18] McGinnis WR, Audhya T, Walsh, WJ. Jackson JA, McLarenHoward J, Lewis A, Lauda PH, Bibus DM, Jurnak F, Hoffer A. Discerning the mauve factor, Part 1. Alternative therapies 2008; 14: 46-62.

[19] Mikirova NA, Casciari JJ, Hunninghake RE. The Orthomolecular Correction of Metabolic Imbalances Found in Attention Deficit Hyperactivity Disorder: A Retrospective Analysis in an Outpatient Clinic. J Orthomolecular Medicine 2013; 28: 1-10.

Received on 24-02-2015

Accepted on 04-03-2015

Published on 14-04-2015

DOI: http://dx.doi.org/10.6000/1929-5634.2015.04.01.2

(C) 2015 Nina Mikirova; Licensee Lifescience Global.

This is an open access article licensed under the terms of the Creative Commons Attribution Non-Commercial License (http://creativecommons.org/licenses/by-nc/3.0/) which permits unrestricted, non-commercial use, distribution and reproduction in any medium, provided the work is properly cited. 